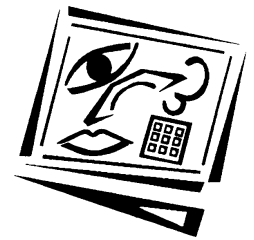

\title{
Implementing an open source learning management system: A critical analysis of change strategies
}

Philip M. Uys

Charles Sturt University

This paper analyses the change and innovation strategies that Charles Sturt University (CSU) used from 2007 to 2009 during the implementation and mainstreaming of an open source learning management system (LMS), Sakai, named locally as CSU Interact. CSU was in January 2008 the first Australian University to implement an open source learning management system institution wide. The unique characteristics of implementing change and innovation in higher education are discussed as well as CSU's change model, which comprises eight dimensions that can occur in any order and also in parallel, and is based on the work of Kotter, Cohen and Synnot. Two key strategies have emerged to support change, namely the building of learning communities and the sharing of best practice in implementing educational technology. Other findings were that the change was largely driven from the bottom up and with top management support and through the writer's role, from middle management in terms of top down strategies. Technological innovations in the context of an open source learning management system have wider, external implications than the local institution given the free flow of information and intellectual property within the community.

\section{Background}

This paper analyses the change and innovation strategies that Charles Sturt University (CSU) used during the implementation and mainstreaming of an open source learning management system (LMS), Sakai (2009), from 2007 to 2009. CSU was in January 2008 the first Australian University to implement an open source learning management system institution wide.

CSU has been experiencing changes in an ongoing way in the 2000s that correspond to the view of Tsoukas and Chia (2002) who "treat change as the normal condition of organizational life". Ramsden (1998) has identified characteristics of academics that make leadership for change difficult; they tend to be suspicious of formal planning, distrustful of management, have low commitment to corporate goals and are trained to question and criticise joint agendas. It is therefore necessary, as Fullan (1991:350) suggests, "... that we explicitly think and worry about the change process" in educational reform and innovation.

At Charles Sturt University, Sakai is called CSU Interact (2009), as this LMS was implemented to increase innovative learner engagement, interaction and interactivity in learning. This open source learning management system replaced a very limited home grown and fragmented system, as part of a broad strategy for innovation in flexible learning. Sakai (2.4) was a major leap forward in the provision of online 
learning technologies at CSU as can be seen through a para-analysis of the impact of technologies over time at CSU (Figure 1). Para-analysis is a strategic approach to mapping technology in an institution over time and provides a way to identify and measure the impact of technology at an institutional level (Buchan, 2010).

Charles Sturt University (2009) is the biggest distance education provider in Australia with 33,000 students in total, while also having thirty percent of its students distributed over a number of campuses for predominantly face to face instruction. CSU has a strong print history but are moving into a blended delivery mode through the use of print and digital media. The University has a number of international campuses and partners who are all using CSU Interact.

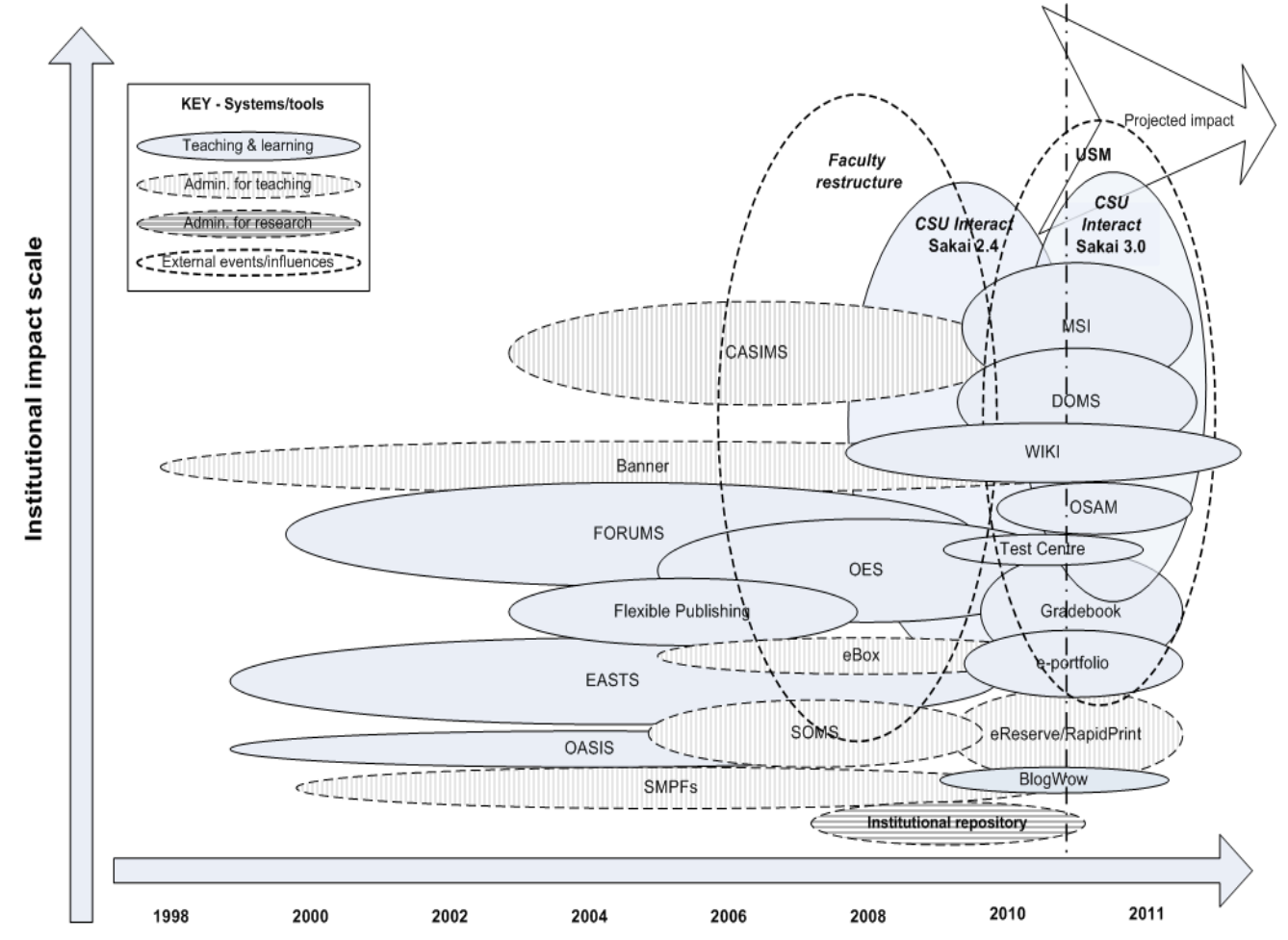

Figure 1: Para-analysis of educational technologies at CSU

The academic staff component consists of full time and casual staff who all need professional development in using CSU Interact. As with most universities worldwide, there is typically a small percentage of academic staff who are front runners in the use of learning technologies while a large percentage of staff move slower when it comes to integrating new learning technologies in their learning designs.

\section{Change and innovation strategies}

The change process reported on started in January 2007 and continued through December 2007, when over 700 academics started to use CSU Interact to January 2008, when 33,000 students engaged in online learning supported by CSU Interact, to 2009 when use of this LMS had been mainstreamed at CSU. 


\section{CSU change and innovation management model}

CSU has adopted a change model (2008) that comprises eight dimensions that can occur in any order and also in parallel - see Figure 2. This model is based on the work of Kotter (1996), Kotter and Cohen (2002) and Synnot (2007). Kotter's model is well established and widely used internationally and also in Australia. This model proved helpful and provided the implementation framework for University-wide, School and divisional change strategies during the implementation of CSU Interact. These dimensions are discussed below as they were applied to the introduction of the open source learning management system.

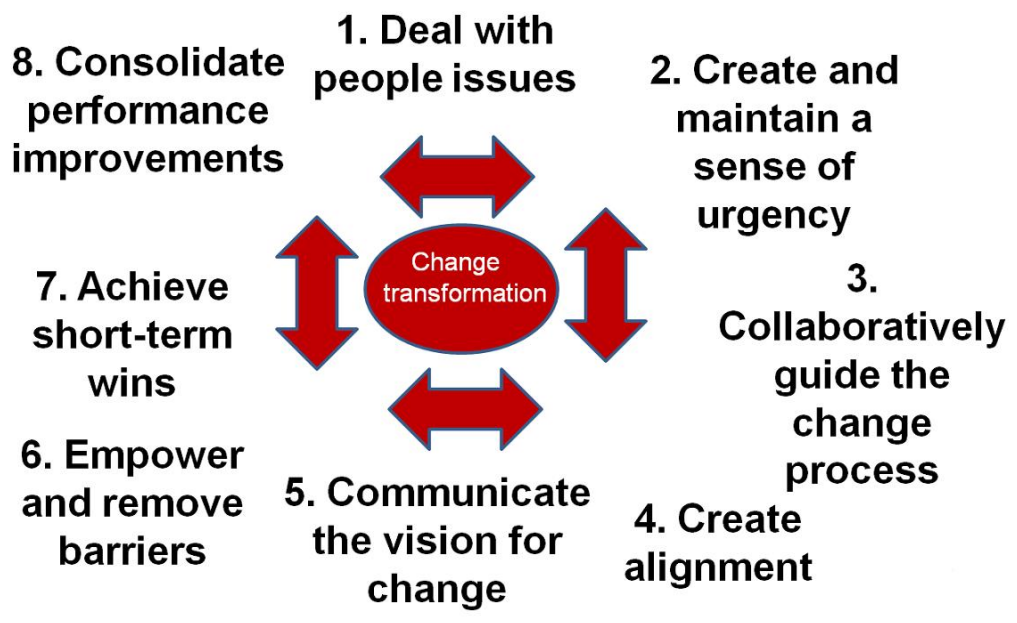

Figure 2: The CSU change model based on the work of Kotter

The first dimension deals with people issues. The majority of academic staff was open to the introduction of a new, integrated online learning environment. It did become, however, evident in some areas that academics have been resisting the full use of CSU Interact that continued in 2009 because of a lack of addressing the perceptions of these academics. It is critical in learning and teaching transformation to address the concerns and perceptions of academic staff in the light of the need for changing their attitudes and to ensuring ownership by academic staff (Evans \& Franz, 1998; Taylor, Lopez \& Quadrelli, 1996). We could have done more through the extensive spread of educational designers to create more ownership in the schools. A clear rationale to address the question "What is in it for me" could have been constructed and widely disseminated. A major structural issue that has not been satisfactorily addressed at CSU is what Marshall (2004) describes as raising the "the status of teaching within the academy and within the community." The counter focus on research often leaves academics ill-motivated to focus their energy on teaching and learning and in particular using an online learning environment like CSU Interact. Very little compensation is provided at CSU for learning and teaching and specifically involvement in ICT-enabled learning, which Marshall (2004) points out as a common issues in educational change.

Dimension two ensures that a sense of urgency is created and maintained. The deadline of 17 December 2007 by which academics developed access to Interact and the 
online version of their subjects, created some urgency. The university wide implementation of this LMS and the communication around it further made it clear to all staff at the university that a new era of online learning had begun. Interact sites were created for all subject offerings and academics have been expected to response online on a weekly basis. Deeper promotion of the positive aspects of Interact could have lead to a heightened sense of urgency. The change process commenced largely as a top down decision, and the change processes therefore lacked intrinsic urgency as it did not initially align with the personal drivers of academics.

The third dimension of the CSU change model calls for a collaborative guiding of the change process. In higher education, 'project management' approaches are put forward as being both desirable and as a means of organising to support the development of ICT-enabled learning and teaching (Bates, 2000). At CSU we called it the Online Learning Environment (OLE) program. The representative Online Learning Environment (OLE) Steering Committee and the OLE Program Team lead the change process. While there was academic representation on the Steering Committee, the Program team had no academic representation. An OLE Reference Group was not created until 2010. The lack of direct academic input in the Program (and also in the selection of Sakai), was in hindsight not the correct approach. There were also guiding teams in some of the administrative divisions. In some of the academic schools implementation teams were formed, but in others the change process was less successful and depended on a few enthusiasts. Change of this extent cannot be driven by a few individuals and more focus should have been placed on school teams.

Creating alignment with University goals is a further dimension of the change model. CSU Interact is seen as instrumental to support CSU's vision to be, by 2011, a leader in the flexible provision of quality learning and teaching. School and divisional based plans for the introduction of CSU Interact were also created. It is vital to answer the question of academics "What's in it for me?" in a change process, and in this process it was not always made clear how academics might benefit from using CSU Interact. The rationale for change at school level was also not always well defined and hampered the uptake of CSU Interact in some schools. School plans could have been created for the implementation of CSU Interact that would have spearheaded learning and teaching innovation. Some faculties, however, created policies that integrated Interact use within blended learning strategies and progressed significantly with online teaching in 2008 and 2009.

Dimension five involves communicating the vision for change. An extensive communication plan was executed successfully across the University to inform all staff and students about CSU Interact. These communications included emailing news messages, formal communications through committees, screensavers and through an extensive professional development plan.

However, Marshall (2004) calls for a "a whole of enterprise approach to the resolution of the problem" which was not fully articulated in the vision and the resultant communication. More should have been made of the need of the need for CSU-wide strategies to implement CSU Interact.

Communication has continued in 2009 mainly through intra-school activities but also through a micro-blogging tool named Yammer (2010) that has continued to play a critical role in the growing ICT-enabled learning community of practice (ICTCOP). 
This has been very popular since its inception in May 2009 - see Figure 3 below. There are now 229 members, who are mostly academics (there are about 750 academics at CSU), and there was a total of more than 1400 messages posted since its inception in May 2009. Yammer is a free program and while externally hosted is closed for use by members of the same email domain - in our case for CSU staff only. It replicates casual conversations and informal discussions that provide the foundational support for more formal activities and that are the most difficult to create in a distributed community (Hinds \& Weisband 2003).

The success of collaborative communication using Yammer is evident from the consistent growth in messages posted in it, staff joining it and actual posters as per Figures 3, 4 and 5. Figure 3 illustrates the rapid growth in Yammer users when CSU started using this micro-blogging tool. Even though the rate of new users joining has levelled out, there is some continuing growth.

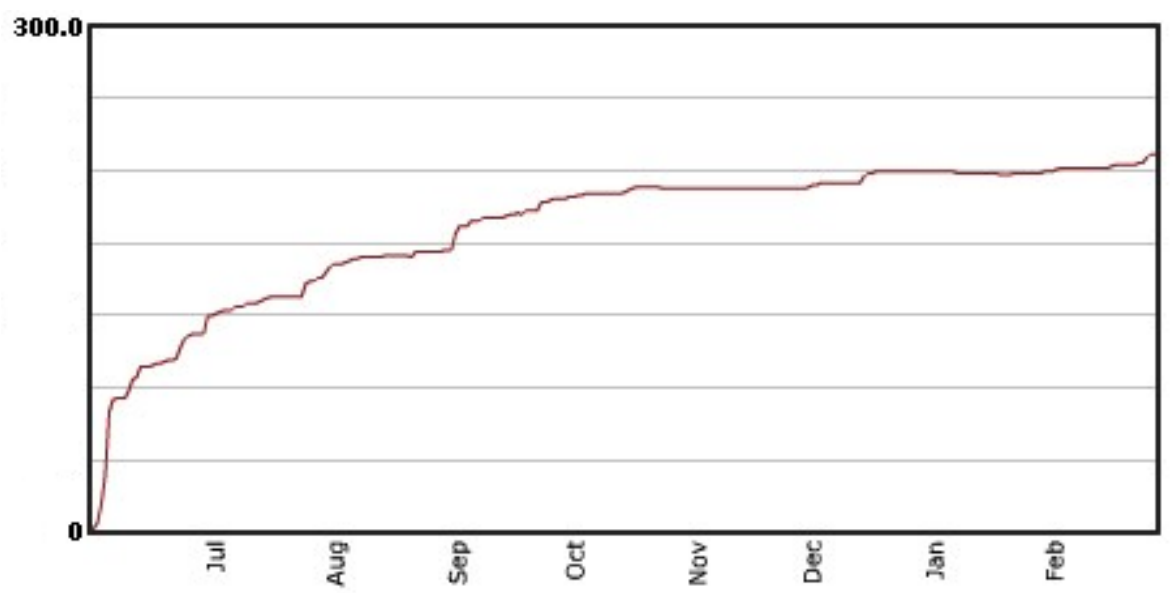

Figure 3: Cumulative total numbers of CSU staff joining Yammer, May 2009 to March 2010

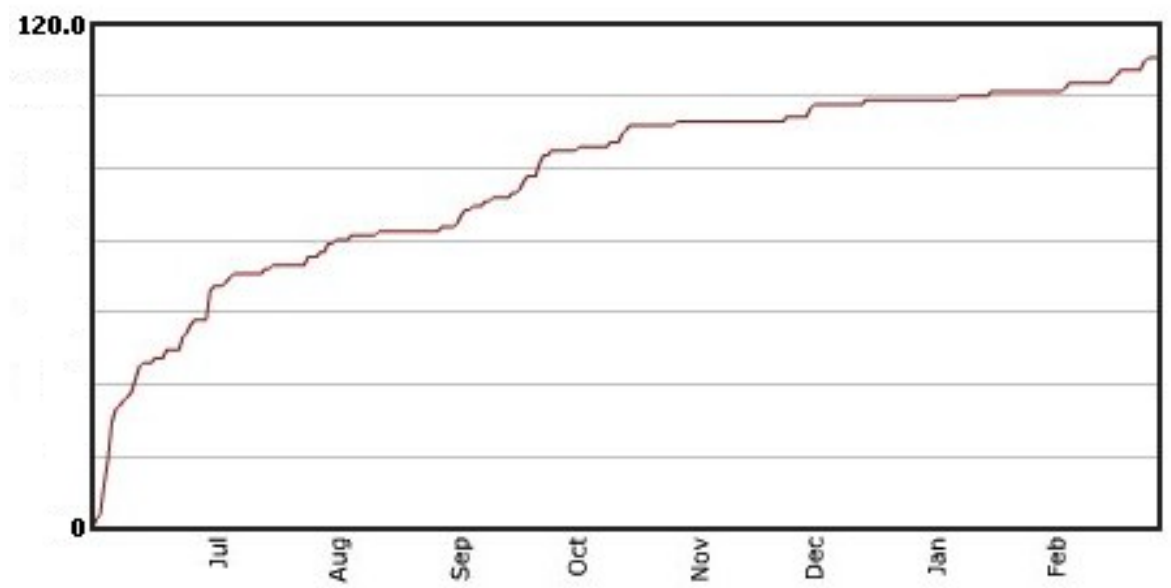

Figure 4: Cumulative total number of posters in Yammer, May 2009 to March 2010 
Figure 4 indicates that the active posters are increasing which is the sign of a healthy community. In ICTCOP it is not the same people that carries the community in terms of posts. Figure 5 clearly illustrates that contributions to Yammer are steadily increasing, as one would expect from as healthy community in its early stages of development.

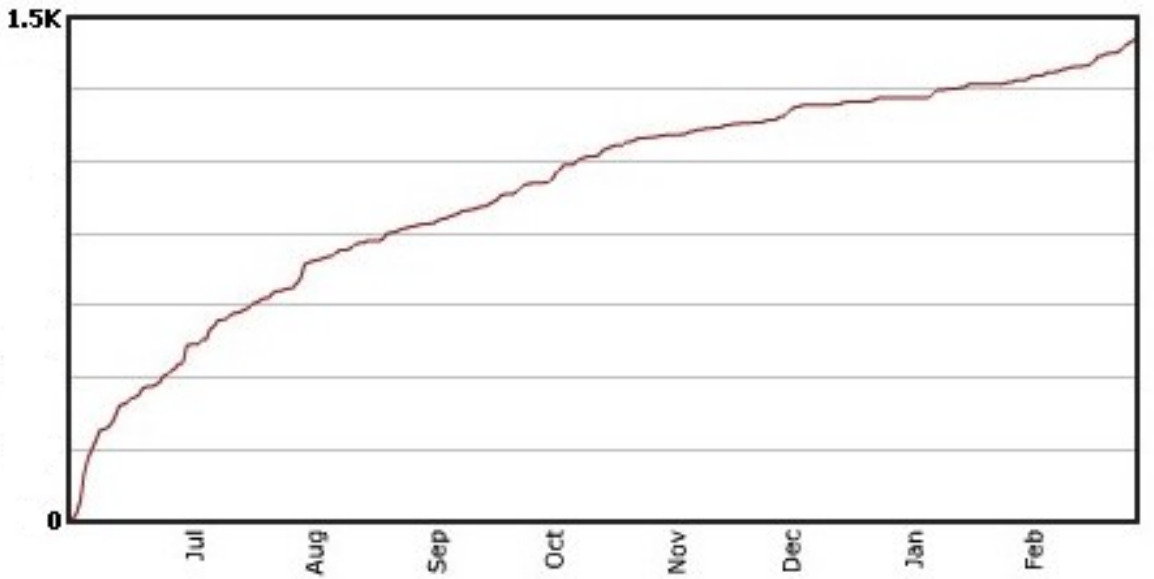

Figure 5: Cumulative total number of micro-blogging messages posted via Yammer, May 2009 to March 2010

In March 2010 I asked the following question in Yammer:

Yammer users - what is the value of Yammer to you? We need this info in considering a contract with Yammer.

Is it

1. Making contacts i.e. networking

2. Getting support from others

3. Supporting others by providing info

4. Sharing what I am doing

5. Accessing postings more than a week old to find information

6. Accessing postings more than a month old to find information

7. Other - please specify:

Simply post the numbers as a reply to this posting and specify "Other" (if applicable).

Below are some of the responses:

Other: being the only place I can put a question out there and get a reply within 5 minutes from someone like .... or two minutes from Philip Uys!

1,2,3,4 \& 7 other - generally keeping up to date with what's happening at CSU.

1-7 a terrific tool to collaborate with

$1,2,3,4 \& 7$ other - I tend to take a really quick look at things people are sharing, but then transfer it to my delicious account if I think it will be useful later on (but don't have time to read now). Saves looking back through old posts to find info. Mostly though it's useful to get a better feel for what others are involved in, so you know who to go to when something pops up (as it does)... 
1,2,3,4,5, 7 - Yammer has certainly connected me to people within CSU that I would not have 'met' online via email or mailing lists. I thank all you Yammer-ers out there for sharing websites, reports etc - it is one of many sources I now use for professional reading. While I don't use Yammer for point 6, I think I would if I belonged to a specific community or was using it as a communication/sharing tool with one of my classes.

$1,2,3,5$ are the predominant uses/ activities for me. I am not a daily 'user' so I tend to find value in the 'conversational' history attribute of the tool.

I don't do much on yammer and delete most of the emails but I'm very glad to have them coming in. I was just alerted to the "Assessment Futures" website from a yammer message which is extremely valuable. We are now planning on running a workshop on this in our school. So my main use of yammer at the moment is just keeping up to date and being alerted to quality information.

Being busy with school activities makes it hard to know what's happening in other schools and other campuses so yammer is really useful in this matter, as a new academic employer yammer was the first place for me to get some of my answers quickly from some experts like Philip which is really appreciated.

The sixth dimension deals with empowering people and the removal of barriers. Extensive professional development occurred successfully across the University and its affiliates and centres, followed by a support plan. The professional development was based on an extensive set of self-help materials about all the tools in CSU Interact. Educational designers ran workshops and drop-in sessions in each of the academic schools. Not many procedural changes were necessary during the initial phases of implementation, except that teaching online using an extensive array of technologies was new to many academics. The policy issues that had to be dealt with included copyright matters, which were addressed as required; use of third party images was complex but was resolved in 2009 though hyperlinking. However, the staff in the division dealing with information technology as well as the division of learning and teaching services have had to alter their work processes to work within an open source community. In 2007, 2008 and 2009 CSU has been mainly a consumer of program code and advice shared in the Sakai community.

Dimension seven focuses on achieving short term wins, which were achieved during the implementation through running pilots, and also through front runners who started using CSU Interact in innovative ways. The pilots covered a wide range of the tools available in CSU Interact. The pilots occurred across all the faculties and provided quick and visible results across the University. The results of these pilots could, however, have been made available more widely.

The final dimension of the change model leads to the consolidation of performance improvements that are supported by a continuing professional development program. Performance improvements occurred in 2009 and beyond as academics designed new and blended learning experiences for students.

During this change process, three key, bottom up strategies emerged:

1. The building of learning communities,

2. Encouraging applied research, and

3. Sharing of best practice. 


\section{Building learning communities}

Gibson and Manuel (2003) argue that effective communication and continued interaction allows those involved to develop common values and a shared understanding based on mutual trust, which is fundamental to building of communities, allowing them to grow, change and achieve objectives. The development of 'learning communities' that engage academics in local communities of discourse about their educational practices provides a sound basis for innovation and reform (Tillema, 1995). If learning communities are to create change, however, they must involve learning at all levels of the organisation. Building trust requires that local 'learning communities' engage in discourse that challenges those responsible for strategic planning and institutional support structures to expand their understanding of the 'messy' (McNaught, 2003) realities of learning and teaching in specific environments and adjust goals and strategies accordingly.

Some communities of practice developed through targeted actions, but this was complex as the Centre for Enhancing Learning and Teaching does not have line authority in academia at CSU. Most initiatives therefore were encouraged and supported by bottom up voluntary efforts. A reasonable success was the community that developed around a general Interact group site about information and communication technologies (ICT) integration called ICTCOP (2009) where just over 500 staff members joined voluntarily. This site became a key communication mechanism for all Interact related matters. It is important in 2010 to change the dynamics and nature of the site to be more collaborative and more participative.

Three University-wide video conference forums to simulate face to face experiences have been held in 2009. The forums have specialist academics and divisional staff presenting on their teaching practice for 10 minutes each, on a theme of general interest followed by discussion. The theme of the first Forum in June 2009 was "Evaluating learning with ICT, and evaluation ICT use in learning and assessment" while the theme of the second forum in August 2009 was "Imaginative online content". The theme of the forum held in November 2009 was "ePortfolios and Personal Learning Systems". Each forum has had between 40 and 70 attendees which is exceptional at CSU. In all cases about 12 video conference facilities were used to link the campuses together. The forums provide University-wide, mediated, face to face interaction as well as some direct face to face interaction opportunities on the different campuses. The forums have led to healthy debates on learning and teaching issues and have inspired academics to experiment with ICTs in their teaching.

The following strategies are being considered to grow and enrich the life of the CSU ICT-enabled learning community (ICTCOP):

1. To invite the community to join a Supporters group that could meet monthly to plan and support the life of the community

2. To continue bi-monthly video conference forums across all campuses for two hours so that a few people can share their stories about ICT integration, followed by an open time where anyone can share/show interesting aspects of their learning and teaching enabled by technology, new technologies on the horizon, worthwhile articles, summaries of presentations at conferences and the like. The presentations could be captured on video and published online in the site "About ICT integration" while the open time discussion items can also be added to the wiki in the site "About ICT integration". 
3. To link to the Institute for Flexible Learning; for example some of the teaching fellows (an annual involvement) could present on their fellowships at the bimonthly forum.

4. A face to face pre-workshop for all members at the annual CSU Learning and Teaching Conferences.

The Sakai open source system links CSU with the wider Sakai technical and user community, which is critical for being up to date with Sakai developments, for more efficient computer code developments and professional development and for contributing back to the community. This engagement has grown in 2009 and is to continue to expand in 2010.

\section{Encouraging applied research}

An applied research institute at CSU, the Institute for Flexible Learning, developed an applied research framework through the "Teaching Scholar" scheme. Eight academics are given the opportunity annually through funding to apply ICT including CSU Interact in their teaching and to disseminate their findings widely in the University. This scheme promotes the scholarship of teaching and is an attempt to circumvent the problem that Marshall (2004) describes as the lower status of teaching within the academy and within the community compared to discipline based research. This scheme continued in 2009 and 2010 and will lead to further applied research into using CSU Interact in learning and teaching.

\section{Sharing of best practice}

Over the years, learning and teaching staff at conferences and at the universities where the writer worked indicated that academics often seem to be more open to change that come from within their own ranks. Educational designers at CSU have also indicated that academics often ask for examples of the work of fellow academics regarding ICTenabled learning. Attempts were thus made to build an online Learning Designs Showcase consisting of comprehensive learning designs involving ICTS, but these efforts were thwarted by delays in the peer review process. In addition the reward structure was not inviting enough. This initiative has expanded in 2009 through a simplified process and have lead to the continual extension of this Showcase, and also the collection of short stories of CSU Interact usage (2009) that proved to be more successful. Educational designers from CELT, of whom every academic school has one, collected these stories from academics and posted it on the wiki in the site 'about ICT integration' where after the stories were categorised and added to a website. This will be continued in 2010 while also adding the "stories" of the bi-monthly forum to this site. Stories from the Sakai community can also be identified and added to this resource.

\section{Unique aspects of educational change}

Adrian Bromage (2006) identified the following unique aspects of educational change and innovation by comparing the literature of change in general with that of educational change.

The first aspect is the need for mutual education to take place. This did occur at CSU in a minor way given the top down decision to implement CSU Interact university-wide from January 2008. Mutual education did, however, occur between academics and 
educational designers in the schools around the details of the implementation and the application of ICT in their teaching.

The second aspect is the imperative to follow a collegiate approach. Given that the change was implemented on grassroots level through academics who worked closely in most cases with educational designers, a collegiate approach was largely followed.

Providing high quality evidence to academics is the third aspect. Not enough work was done in this area due to attention to other aspects of the change program; this lead to a lukewarm reception of CSU Interact. This lukewarm reception was eventually countered in many cases due to the close and committed support by school-based educational designers. Case studies of the implementation and use of Sakai and other online learning environments at other institutions nationally and internationally could have been helpful in achieving more extensive buy-in.

Bromage posits lastly that a spirit of open debate should occur for educational change to be effective. This aspect was not possible on the higher levels of decision making given the top down decision to implement CSU Interact university-wide from January 2008. Debates did occur about how to integrate CSU Interact in subjects though, between academics and educational designers. Ramsden (1998) suggests that the enterprise culture, by retaining a significant role for decision making at the level of the academic organisational unit, can be both responsive to the changing educational environment while retaining enduring academic values. Uys and Tulloch (2007) point out that in changes related to learning technologies, however, the balance of tight and loose control over implementation is a particularly challenging one, because the institutional imperatives around a centralised approach to IT infrastructure provision can militate against the engagement of academics in changing their teaching, upon which any effective implementation of learning technologies ultimately depends on.

This dynamic, also called the interplay between bottom up and top down change approaches, is well captured in the LASO model.

\section{LASO model}

The LASO (Leadership, Academic and Student Ownership and Readiness) Model for Technological Transformation in Tertiary Education (Uys, 2007) can be used to evaluate the implementation of Sakai at CSU. This model acted as an additional guide for the writer to the change and innovation management process at CSU.

The LASO model (see Figure 6) emphasises the importance of integrated top down and bottom up processes, which is also proposed by Gunn (1998) and Fullan (1991:349) who refer to this dilemma as the tension of "... combining individual and institutional development...". The LASO model suggests that technological transformation occurs when leadership is integrated with academic and student ownership and readiness. Leadership is achieved through mechanisms such as defining a clear vision for the transformation, providing a reward structure for those engaging in the change process, and the creation of a strategic framework to guide the transformation.

In summary, looking at the implementation in the light of the LASO model, various top down and bottom up strategies were used. Top down strategies included linking and adhering to the CSU Strategic Plan 2007-2011 (2006a) and the CSU Learning and 
Teaching Plan (2006b). There have been a Steering Committee and a Program Team governing the implementation. The Deans and Heads of Schools were briefed at critical points. The inevitability created through the top down decision that CSU Interact will be used University-wide from the beginning of 2008 created further top down impetus. The CSU experience confirms the view of Berge and Schrum (1998) that the key to successful campus initiatives in technology-enhanced learning and distance education is the support of campus leaders. This further correlates with Drucker's (1985) assertion that a successful innovation should aim at leadership from the beginning in order to be innovative enough and capable of establishing itself.

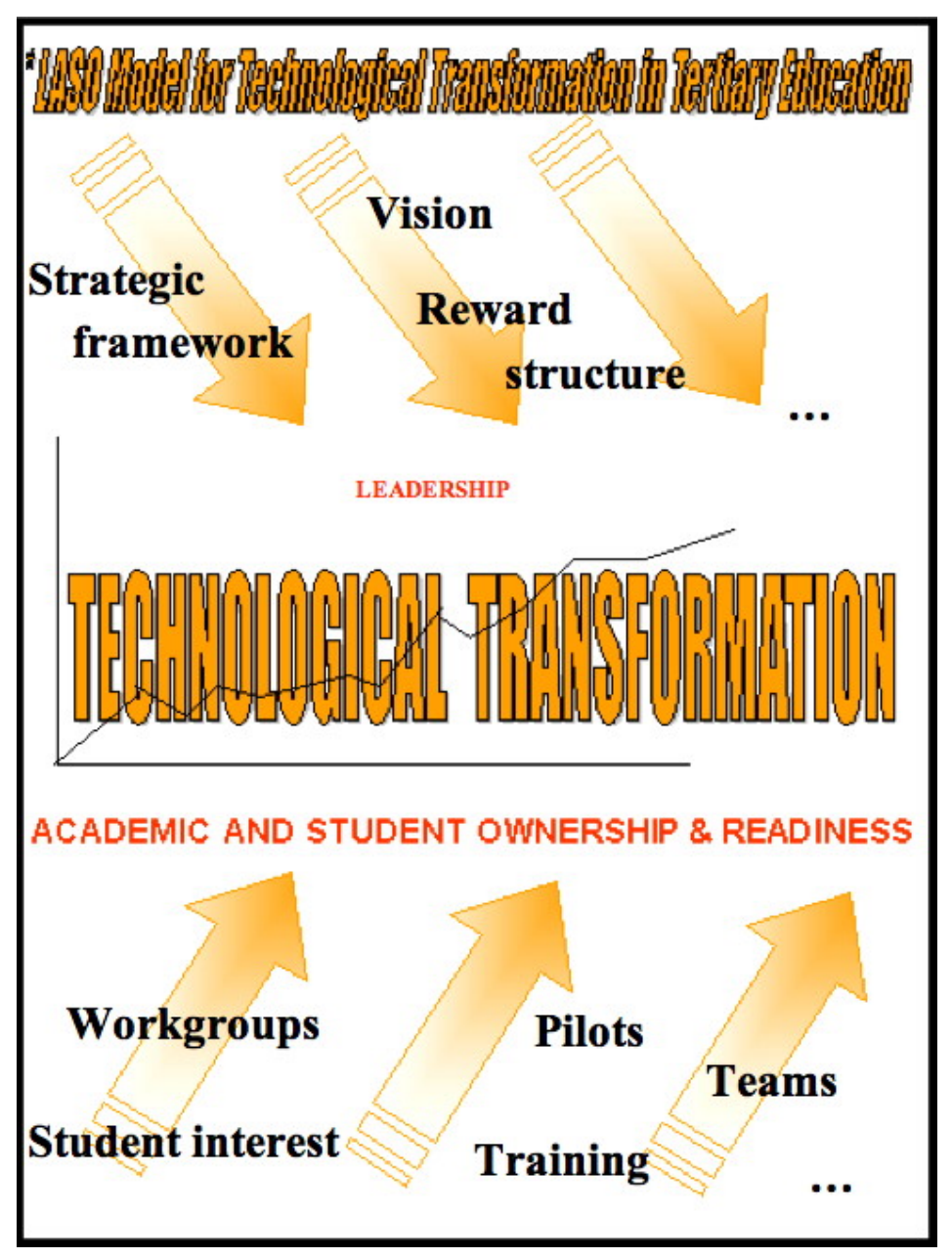

Figure 6: The LASO Model

Involving the heads of the just over 30 schools could have made for a much stronger change process. Academic middle management, they heads of academic schools, were not adequately prepared and did not play the crucial role they could have played in motivating academic staff and resourcing change. It was thus incumbent on schoolbased educational designers and the academics involved in the pilots to be agents of change. Cummings et al (2005) reported that a middle-out approach was effectively 
used at Murdoch University where "middle managers became leaders and, through a combination of personal inspiration and policy based on emergent practice, have changed the university environment sufficiently to force both high level policy change and change in practice among teaching staff." The change at CSU was driven from the most senior staff with matching bottom up initiatives, and through the writer's role and other members of the program team from middle management.

Tillema (1995) points out that historical studies, based largely on experience in schools, show that top down attempts to achieve educational reform have failed, and suggests that they will be doomed to failure until they deal with the cultural and pedagogical traditions and beliefs underlying current practices and organisational arrangements. Bottom up strategies are therefore critical and at CSU these included running pilots, extensive professional development, wide communication also with students, as well as the extensive support provided by the educational designers across the University. The bottom up strategies were, however, varied in their success and reach as they did not clearly address the "What's in it for me" question of academics and could have propelled CSU further in blended and flexible learning.

\section{Professional development}

Professional development (PD) is critical in empowering academics for participation in innovation and educational change. This program was very successful and prepared academic staff, on which the professional development was focussed well for using Interact. One of the reasons for this success was that the Centre for Enhancing Learning and Teaching (CELT - of which the writer was a member) had a couple of staff dedicated to the PD program who developed PD materials and ran workshops. The PD sessions in the schools occurred in late 2007 with some repeats occurring in 2008 and 2009. The educational designers have also been providing one on one professional development and support.

Being part of a worldwide Sakai user community allowed us to use already developed PD materials from the Sakai community. We built extensive online resources through a "Help" site using frequently asked questions (FAQs). The CSU Interact site "About ICT integration' linked to all the PD materials and allowed for questions to be posted. A staff support site was created with extended support materials that are being widely used.

Many academics were deeply involved though pilots, as participants in the PD program and through immersion through project sites (for example for use for research) in CSU Interact. Academics also held 'brown bag' lunch time meetings in schools and shared their experiences in the pilots. PD of CSU Interact has further been built into the official Foundations of University Learning and Teaching program - a program which is compulsory for all new teaching staff. A wide range of sessions on the use of CSU Interact were presented at the face to face 2008 and 2009 CSU Learning and Teaching conferences.

Training for students occurred through an immersion approach where students learned about CSU Interact during the process of accessing information on student life at CSU, and through academics. Students also learned to use the online tools through actual use, given that the tools are less complex from the student perspective (while it is more complex for academics in setting up materials). 
In the divisions a variety of PD strategies were used such as workshops, building Interact project sites, linking learning to performance management, and self-study.

\section{Communication}

Communication is central to successful participation in educational change and innovation. The communication in this program was effective and no academic staff member or student could legitimately claim not to have known about Interact in general and a few specific aspects. The communication program was integrated in the change management and PD processes with a central communications team conveying messages during 2007 and 2008. Communication to students occurred at key points through an efficient system whereby all students of the University are individually emailed via a computerised system. Computer screensavers were implemented for all staff and students. Various communication strategies were used in the divisions such as briefing sessions and representation on the central Interact Communications Team.

Kotter and Cohen (2002) emphasise that change management approaches should focus on both rational approaches as well as on the affective domain through 'see-feelchange' strategies. In this regard a CD in which academics who participated in the pilots shared their stories and senior administrators in the University shared their vision for Interact was provided to each academic. Bottom up communication with academic staff further occurred University-wide through educational designers and via Learning and Teaching committees in the schools and faculties.

An extensive Interact website (2009) was created as a pull strategy with professional development materials, general information about Interact, the range of tools available and information on pilots. The latest news were distributed via announcements and the listserv in the site 'About ICT integration'.

Communication systems require a feedback loop. In the Interact program the feedback was provided primarily by the educational designers. At the end of 2008 an extensive review was carried out among academic staff that indicated a reasonable level of acceptance and use of the system. Sporadic feedback from staff and students also occurred on online forums. The feedback was valuable in rectifying system problems and implementing new features.

The public and academic community in general were informed about the positive use of Interact through a few official releases, some newspaper articles and presentations at conferences.

\section{Summary}

The change was largely driven from the most senior staff and though matching, bottom up strategies, and through the writer's role from middle management. During this change and innovation process it was noticeable that the known 'movers and shakers' engaged in the process as early adopters (Rogers, 1995). The academic middle management, however, was not adequately prepared and did not play the crucial role they could have played in motivating academic staff and resourcing change as is the case when 'middle-out' strategies are effectively used. As indicated in the LASO model, a multi-pronged approach addressing top down, bottom up and middle-out strategies has more potential for success. The success of bottom up strategies were 
varied, for example the results from the pilots were not widely communicated, and educational designers had varied success in the academic schools.

CSU's change model (2008), however, proved helpful and provided an extensive framework for University-wide change strategies, School strategies and divisional strategies. More than one change dimension has been addressed at the same time and we experienced that "to properly understand organizational change one must allow for emergence and surprise" (Tsoukas \& Chia, 2002), as some "unknown" academics, for instance, became prominent through their excellent online teaching.

Educational change and innovation and the related key strategies in change management, professional development and communications, needs to deal first and foremost with people issues such as innovation capacity, insecurity, resistance, and technophobia during the change process. The ragged contour of technological transformation as depicted in the LASO model above has also been confirmed at CSU in contrast to the smooth contours predicted in Rogers' (1995) diffusion of innovation curve. Difficulties in human relationships, varied success in schools, change fatigue, resistance to change among staff, and dealing with diverse expectations all contributes to the complexity of implementing and using learning technologies at CSU.

Technological innovation in the context of an open source learning management system has wider, external implications than the local institution, given the free flow of information and intellectual property within such an international community.

The expected learning and teaching innovations that CSU Interact need to support are still being realised. The change process in general has been successful with CSU Interact being widely used throughout the University. At the annual CSU learning and teaching conferences, many presentations describe how CSU Interact has been used to create deeper engagement by the learners, especially for our distance students. CSU Interact has also lead to more flexibility in the students' learning through the range of technologies that are provided.

However, the structural issue of raising the status of teaching within the academy at CSU vis a vis the focus on research with related compensation strategies, still needs to be addressed satisfactorily, for the potential of CSU Interact to be realised to transform learning and teaching. If it is true that "the biggest temptation is to settle for too little" (Merton, 2009), then CSU needs to continue to aggressively extend the educationally focussed implementation and support of CSU Interact in learning and teaching, to create richer learning experiences for the students, so that educational technology effectively serves the purposes of learning.

\section{References}

Bates, A.W. (2000). Managing technological change: Strategies for college and university leaders. San Francisco, CA: Jossey Bass.

Bromage, A. (2006). The management of planned change: An interdisciplinary perspective. In L. Hunt, A. Bromage \& B. Tomkinson, (Eds.), The realities of change in higher education: Interventions to promote learning and teaching. London: Routledge.

Berge, Z. L. \& Schrum, L. (1998). Strategic planning linked with program implementation for distance education. CAUSE/EFFECT, 21(3), 31-38. 
Buchan, J. (2010). Putting ourselves in the big picture: A sustainable approach to project management for e-learning. The Journal of Distance Education, 24(1), 55-76. [verified 18 Dec 2010] http:/ / www.eric.ed.gov:80/ PDFS/EJ892356.pdf

Charles Sturt University (2006a). University Strategy 2007-2011. [viewed 27 November 2010] http: / / www.csu.edu.au/division/vcoffice / papers / docs / strategic_plan_2007-2011.pdf

Charles Sturt University (2006b). Learning and Teaching Plan 2007-2011. [viewed 27 November 2010] http:/ / www.csu.edu.au/division/landt/ policy/ltplan.htm

Charles Sturt University (2009). http: / / www.csu.edu.au/ [viewed 27 March 2010]

Cummings, R., Phillips, R., Tilbrook, R. \& Lowe, K. (2005). Middle-out approaches to reform of university teaching and learning: Champions striding between top-down and bottom-up approaches. The International Review of Research in Open and Distance Learning, 6(1). http: / / www.irrodl.org/index.php/irrodl/article/view/224/307 [viewed 11 Dec 2010]

CSU Interact (2009). http: / / www.csu.edu.au/division/landt/interact/

Drucker, P. F. (1985). Innovation and entrepreneurship. London: Heinemann.

Evans, F. J. \& Franz, J. B. (1998). Managing change in the global university. In proceedings of Towards the Global University: Strategies for the Third Millennium Conference, April. Tours, France: University of Central Lancashire.

Fullan, M. G. (1991). The new meaning of educational change. 2nd edition. London: Cassel Education Ltd.

Gibson, C. B. \& Manuel, J. A. (2003). Building trust: Effective multicultural communication processes in virtual teams. In C. B. Gibson \& S. G. Cohen (Eds), Virtual teams that work. San Francisco: Wiley and Sons (pp. 59-86).

Gunn, C. (1998). Virtual technologies in higher education: Vision or reality? In M. Peters \& P. Roberts (Eds.), Virtual technologies and tertiary education. London: Routledge (pp. 134-145).

Hinds, P. J. \& Weisband, S. P. (2003). Knowledge sharing and shared understanding in virtual teams. In C. B. Gibson \& S. G. Cohen (Eds), Virtual teams that work. San Francisco: Wiley and Sons.

Interact group site (2009). http: / / interact.csu.edu.au / [viewed 27 March 2010]

Kotter, J. P. (1996). Creating the guiding coalition: Leading change. Boston, Mass: Harvard Business School Press. (pp.51-59, 19-23).

Kotter, J. P. \& Cohen, D. S. (2002). The heart of change. Harvard Business School Press.

Managing Change @CSU. CSU Organisational Change and Renewal Framework (2008). http: / / www.csu.edu.au / division/humres/org-dev/Change/ChangeFramework.pdf [viewed 21 Jan 2009]

Marshall, S. J. (2004). Leading and managing the development of e-learning environments: An issue of comfort or discomfort? In Beyond the comfort zone: Proceedings ASCILITE Perth 2004. http:/ / www.ascilite.org.au/conferences/perth04/procs/marshall-keynote.html

McNaught, C. (2003). Innovation and change in higher education: Managing multiple polarities. Perspectives, 7(3), 6-82. 
Merton, T. (2009). Wikipedia [specific source not identified] http:/ / en.wikipedia.org/wiki/Thomas_Merton

Ramsden, P. (1998). Learning to lead in higher education. London: Routledge.

Rogers, E. (1995). Diffusion of innovations. 4th ed. New York: Free Press.

Sakai (2009). http: / / www.sakaiproject.org/ [viewed 21 Jan 2009]

Short stories of CSU Interact usage (2009). [viewed 21 Jan 2009] http: / / www.csu.edu.au/division/landt/interact/staffsupport/examples.htm

Synnot, B. (2007). Successful organisational transition. A workshop for Charles Sturt University, September 2007.

Taylor, P., Lopez, L. \& Quadrelli, C. (1996). Flexibility, technology and academics' practices: Tantalising tales and muddy maps. Evaluations and Investigations Programme, Department of Employment, Education, Training and Youth Affairs, Canberra. [viewed 20 Jun 1998, verified 18 Dec 2010]. http:/ / www.dest.gov.au/sectors/higher_education/publications_ resources/profiles/archives/flexibility_technology_academics_practices.htm

Tillema, H. H. (1995). Changing the professional knowledge and beliefs of teachers: A training study. Learning and Instruction, 5, 291-318).

Tsoukas, H. \& Chia, R. (2002). On organizational becoming: Rethinking organizational change. Organization Science, 13, 567-82.

Uys, P. M. (2007). LASO (Leadership, Academic and Student Ownership and Readiness) model for technological transformation in tertiary education, 2001. [viewed $28 \mathrm{Feb} 2003$, verified 18 Dec 2010]. http: / / www.globe-online.com/philip.uys/LASOmodel.htm

Uys, P. M. \& Tulloch, M. K. (2007). Appropriate change leadership for the introduction of flexible learning within university governance and strategic leadership frameworks: A comparative analysis of case studies in developed and developing countries. Integrating for Excellence 3rd International Conference. 27-28 June, Sheffield Hallam University.

Yammer (2010). http: / / www.yammer.com [viewed 27 Nov 2010]

Dr Philip Uys, Director, Strategic Learning and Teaching Innovation

Division of Learning and Teaching Services (LTS)

Charles Sturt University, PO Box 883, Orange, NSW 2800, Australia

Email: puys@csu.edu.au Web: http: / / www.csu.edu.au/division/lts / 